\title{
PERFIL DE CRIANÇAS QUE MANIFESTAM AGRESSIVIDADE NA EDUCAÇÃO INFANTIL
}

Viviane Barrozo Manfré, Andreia Cristiane Silva Wiezzel

Universidade Estadual Paulista - UNESP, Curso de Pedagogia, Presidente Prudente, SP. E-mail: vivianemanfre12@gmail.com

$\mathrm{PIBIC} / \mathrm{CNPq}$

\section{RESUMO}

Tendo em vista que a agressividade vem aparecendo de maneira surpreendente no contexto da Educação Infantil, esse trabalho visou apresentar dados parciais de uma pesquisa que tem como objetivo central investigar as características gerais de funcionamento emocional, personalidade e entorno de crianças que manifestam agressividade excessiva na educação infantil. Para atingir os objetivos propostos, foram considerados, nesta pesquisa de natureza qualitativa, dez crianças com manifestações agressivas, com a faixa etária de quatro e seis anos, de duas Escolas Municipais de Presidente Prudente. O processo de coleta de dados envolveu a aplicação de questionários aos pais e professores, relatórios de observações realizadas em sala de aula e durante os intervalos e atividades lúdicas com as crianças participantes, sendo os resultados mais significativos discutidos e refletidos à luz da teoria de Winnicott.

Palavras-Chave: Crianças; Manifestações agressivas; Educação Infantil; Características gerais; Entorno.

\section{PROFILE OF CHILDREN WHO EXPRESS AGGRESSIVE IN CHILDREN EDUCATION}

\begin{abstract}
Considering that aggressiveness has been appearing surprisingly in the context of Early Childhood Education, this work aimed to present partial data from a research that has the main objective to investigate the general characteristics of emotional functioning, personality and environment of children who manifest excessive aggression in education child. To reach the proposed objectives, ten children with aggressive manifestations, aged four and six, from two Municipal Schools of Presidente Prudente were considered in this qualitative research. The data collection process involved the application of questionnaires to parents and teachers, reports of observations made in the classroom and during playful intervals and activities with participating children, the most significant results being discussed and reflected in the light of Winnicott's theory.
\end{abstract}

Keywords: Children; Aggressiveness; Child education; Teachers; Parents. 


\section{INTRODUÇÃO}

O artigo se refere a dados parciais de uma pesquisa de iniciação científica que resultou de um projeto de pesquisa da docente orientadora, no qual buscou investigar as manifestações de agressividade em salas de aula na educação infantil e os impactos do brincar ao desenvolvimento emocional das crianças, de modo a contribuir com a melhoria de suas relações interpessoais. Considerando o amplo material obtido nessa pesquisa, a pesquisa ora relatada surgiu com o intuito de construir um perfil das crianças que manifestam agressividade. A partir dos resultados finais deste estudo buscaremos discutir possibilidades de auxílio às crianças, famílias e professores, com a intenção de contribuir à melhoria das relações interpessoais.

O objeto de estudo que propomos discutir, isto é, a agressividade, é relevante à medida que muitos professores se queixam de manifestações agressivas de crianças no contexto escolar, o que acarreta dificuldades de relacionamento em sala de aula, por vezes, prejudicando o desempenho dessas crianças. O trabalho com essas crianças se configura grande desafio aos professores, já que, muitas vezes, não possuem conhecimento suficiente sobre a temática em seus cursos de formação, de forma a compreender e lidar bem com essas situações.

Para Winnicott (2005) a agressividade, na maior parte das vezes, está relacionada a aspectos emocionais, o que leva as crianças a buscarem no contexto escolar formas de auxílio, utilizando, para isso, atitudes agressivas para que as pessoas as ajudem a retomar seu desenvolvimento emocional.

Winnicott (1982) destaca que a base para um desenvolvimento emocional saudável perpassa o vínculo materno. Para que os bebês cresçam e se tornem adultos seguros, independentes e saudáveis, é importante assegurar uma boa experiência inicial, por meio do amor entre a mãe e o seu bebê, sendo essa relação iniciada ainda no ventre.

A agressividade não é concebida como algo ruim, uma vez que constitui força necessária aos processos adaptativos do ser humano. Para Winnicott $(1982,2005)$ a agressividade faz parte da essência humana, um elemento fundamental no decorrer do processo evolutivo. Ela é importante no desenvolvimento quando convertida em fonte de energia para realizar trabalhos como a arte, a brincadeira, o estudo etc., resultando em habilidades e características indispensáveis ao desenvolvimento emocional, bem estar psíquico e, também, às relações interpessoais. A agressividade é prejudicial apenas quando não bem é administrada pelo indivíduo ao longo de seu desenvolvimento emocional, podendo gerar dificuldades em suas relações interpessoais.

A criança que apresenta manifestações agressivas excessivas demonstra que alguma ocorrência a tornou incapaz de controlar seu potencial agressivo, transformando-o em uma agressividade benéfica. Winnicott (2005) explica que o bebê, desde seu nascimento, possui muitas necessidades físicas e emocionais que precisam ser atendidas pela mãe ou pela professora na escola. Estes cuidados, muitos dos quais extrapolam o aspecto físico, são muito importantes para sua saúde mental e formação de personalidade da criança, influenciando em sua capacidade de se relacionar com outras pessoas em diversos contextos.

Os relacionamentos da criança são marcados pelas características das relações vivenciadas em seu lar. No que se refere ao aspecto emocional, se essas relações não tiverem uma estabilidade, a tendência é que fique difícil à criança se deparar com seus impulsos agressivos. Os conflitos decorrentes de casos em que a criança não possui um lar suficientemente bom, podem resultar em manifestações agressivas no ambiente escolar. Nesse contexto, a criança tentará buscar as circunstâncias das coisas antes de ter tido seu desenvolvimento saudável interrompido, de modo a solicitar aos lugares externos que cuidem dela.

O processo de elaboração da agressividade é longo, perpassando a maior parte do período em que a criança frequenta a educação infantil. Desta forma, as manifestações agressivas são importantes indicativos de como encontra-se o desenvolvimento emocional da criança. 
A partir do momento em que conhecemos a subjetividade das crianças que manifestam agressividade, nos deparamos com a possibilidade de atuar de forma direcionada, em busca de tornar mais significativas as relações interpessoais na escola, o que é de extrema relevância para o desenvolvimento emocional. Com esse conhecimento, é possível, também, rever posturas dos pais, que não podem delegar a responsabilidade pela educação das crianças somente à escola, visto que seu papel na vida das crianças é indispensável e insubstituível. Ressaltamos a importância de um trabalho em conjunto entre pais e escola, pois, os acontecimentos de um ambiente se refletem no outro.

Neste contexto, o objetivo geral da pesquisa consistiu em investigar as características gerais de funcionamento emocional, personalidade e entorno de crianças que manifestam agressividade excessiva na educação infantil, elaborando uma caracterização dessas crianças.

\section{MÉTODOS}

No que se refere aos sujeitos participantes da pesquisa, foram considerados dez casos de crianças - com a faixa etária entre quatro e seis anos - de duas Escolas Municipais do interior de São Paulo, que apresentavam características acentuadas de agressividade na instituição escolar. 0 projeto foi aprovado pelo Comitê de Ética em Pesquisa da FCT - Unesp (№ CAAE 31996114.5.0000.5402).

O processo de coleta de dados, nesta pesquisa de natureza qualitativa, envolveu a seleção de informações obtidas por meio de questionários aplicados aos pais e aos professores, relatórios de observação realizadas em salas de aula e durante os intervalos e de atividades lúdicas realizadas com as crianças participantes.

A pesquisa qualitativa conforme Bogdan e Biklen (1982 apud LÜDKE; ANDRÉ,1986, p.13), "[...] envolve a obtenção de dados descritivos, obtidos no contato direto do pesquisador com a situação estudada, enfatiza mais o processo do que o produto e se preocupa em retratar a perspectiva dos participantes".

A riqueza da pesquisa qualitativa consiste no fato de que, considerando os objetivos a serem alcançados, é proposto investigar o movimento das pessoas e analisar o contexto na qual elas encontram-se inseridas, pois influenciam muito em suas formas de ser e sentir. Assim, a ênfase nesta abordagem metodológica não recai sobre o resultado, mas sim, sobre todo o processo.

Os dados obtidos foram cotejados e analisados conforme os preceitos da pesquisa qualitativa e, os resultados mais significativos, foram discutidos e refletidos à luz da teoria de Winnicott.

\section{RESULTADOS}

Dentre as dez crianças analisadas, $70 \%$ (o que equivale a sete crianças) estavam na faixa etária entre quatro e cinco anos e moravam com os pais. A maior parte delas, no caso $90 \%$, era do sexo masculino. Estavam distribuídas nas salas de Pré I e Pré II, predominantemente no período integral e eram assíduas à escola. Tanto os pais quanto os professores relataram que elas eram "agitadas", já que o tempo todo eram muito ativas do ponto de vista motor e psíquico. Também, afirmaram que a maior parte delas apresentavam inconstância no humor.

Conforme relato dos pais, todas as crianças gostam de ir à escola e, na perspectiva dos professores, a maioria delas estabelece um bom relacionamento com eles.

Com relação as características gerais de personalidade, as crianças se apresentam "nervosas" em casa, do ponto de vista dos pais, e, também, em menor proporção, ansiosas e tensas: 


\begin{tabular}{l|l|l} 
Categoria & Frequência & Porcentagem \\
\hline Nervosa & 4 & $40 \%$ \\
\hline Os dois & 2 & $20 \%$ \\
\hline Nervosa/ansiosa & 2 & $20 \%$ \\
\hline Não respondeu & 1 & $10 \%$ \\
\hline Tenso & 1 & $10 \%$ \\
\hline Total & 10 & $100 \%$
\end{tabular}

*Conforme questionários dos pais.

Os conflitos emocionais das crianças podem ser identificados por meio de situações que causaram intenso sofrimento à elas:

Fatos na vida das crianças que ocasionaram sofrimento intenso

\begin{tabular}{l|l|l} 
Categoria & Frequência & Porcentagem \\
\hline Não houve fatos & 3 & $30 \%$ \\
\hline Não tem contato com o pai & 2 & $20 \%$ \\
\hline $\begin{array}{l}\text { Agressão física por parte do } \\
\text { avô }\end{array}$ & 1 & $10 \%$ \\
\hline Criança sofreu acidente & 1 & $10 \%$ \\
\hline Morte do tio & 1 & $10 \%$ \\
\hline Separação dos pais & 1 & $10 \%$ \\
\hline Mãe presa & 1 & $10 \%$ \\
\hline $\begin{array}{l}\text { Total } \\
*\end{array}$ & 10 & $100 \%$
\end{tabular}

*Conforme questionários dos professores.

No aspecto geral, as crianças se comportam em sala de aula com "agitação", falta de concentração, com dificuldades em cumprir regras, e, ainda, "não tem limites" - conforme os professores.

Características de comportamento das crianças em sala de aula

\begin{tabular}{l|l|l} 
Categoria de falta de & Frequência & Porcentagem \\
\hline $\begin{array}{l}\text { Agitada; dificuldades } \\
\text { concentração, } \\
\text { em cumprir regras }\end{array}$ & $50 \%$ \\
\hline Não tem limites & 2 & $20 \%$ \\
\hline Inquieta & 1 & $10 \%$ \\
\hline $\begin{array}{l}\text { Explosiva, chora muito para os } \\
\text { Pouco disposta patos }\end{array}$ & 1 & $10 \%$ \\
\hline $\begin{array}{l}\text { Total } \\
\text { *Conforme questionários dos professores. }\end{array}$ & $10 \%$ \\
\hline
\end{tabular}

As crianças expressam agressividade de formas diversas, por meio de ataques verbais e físicos. Os professores destacam possuir dificuldades em lidar com algumas características das crianças, assim como apresenta a tabela: 
Existência de atitudes da criança que são consideradas "delicadas" ou "complicadas" de lidar

\begin{tabular}{l|l|l} 
Categoria & Frequência & Porcentagem \\
\hline Teimosia & 2 & $28,5 \%$ \\
\hline Falta de concentração & 1 & $14,3 \%$ \\
\hline Mau humor de diante de & 1 & $14,3 \%$ \\
\hline $\begin{array}{l}\text { Agressividade } \\
\text { contrariedade }\end{array}$ & $14,3 \%$ \\
\hline $\begin{array}{l}\text { Conflitos por materiais, } \\
\text { brinquedos }\end{array}$ & 1 & $14,3 \%$ \\
\hline $\begin{array}{l}\text { Quando criança fala sobre } \\
\text { sua vida pessoal }\end{array}$ & 1 & $14,3 \%$ \\
\hline $\begin{array}{l}\text { Total } \\
\text { Conforme questionários dos professores. }\end{array}$ & $100 \%$
\end{tabular}

A seguir, será apresentada uma discussão acerca dos dados expostos anteriormente, visando compreendê-los a partir da teoria winnicottiana.

\section{DISCUSSÃO}

Os dados analisados evidenciaram que a maior parte das crianças investigadas possuem uma rotina semelhante; grande parte delas passa tempo maior no espaço escolar do que nos seus respectivos lares, mostrando a importância da escola e o espaço que esta ocupa no desenvolvimento das crianças.

A maior parte das crianças mora com seus respectivos pais e mães, contrariando a afirmação corrente entre os professores de que as crianças que manifestam agressividade morem apenas com um dos pais. Winnicott (1982) explica que, pouco importa a constituição familiar, pois, não é a presença da estrutura de família "ideal" que irá garantir o bom desenvolvimento emocional das crianças, mas, a qualidade dos relacionamentos estabelecidos em família, oportunizando a elas o suporte necessário e seguro.

Para Winnicott (1982; 2005), a agressividade pode estar relacionada à ocorrências no âmbito das relações interpessoais da criança, sobretudo na primeira infância. Os conflitos emocionais que as crianças investigadas apresentam, podem ser identificados por meio de situações que Ihes causaram sofrimento intenso. Vale destacar que a maioria destas situações muitas vezes não podem ser previstas ou evitadas pelas famílias, porém, causam interrupções nas relações estabelecidas entre a criança e a família, desestabilizando-as. A instabilidade emocional está associada à "agitação", inconstância no humor, nervosismo, tensão, falta de concentração e em dificuldades em cumprir regras por parte das crianças investigadas.

Por último e não menos importante, nessa mesma linha, além de fatos potencialmente traumáticos ocorridos na infância (mortes, acidentes envolvendo a criança, prisão ou separação dos pais) - que causam um rompimento brusco nas relações afetivas - a agressividade pode ter seu desenvolvimento prejudicado na presença das seguintes características presentes nos cuidadores: pais permissivos, hiperativos, impacientes, agressivos, "agitados" e distantes emocionalmente. Essas condutas tendem a prejudicar o desenvolvimento da segurança e confiança nos relacionamentos, tendo a criança dificuldade em administrar seus impulsos agressivos e a se relacionar com as pessoas.

À luz da teoria estudada percebe-se que as crianças manifestam agressividade de forma física e verbal, visando obter atenção e ajuda do ambiente em que se encontram inseridas. Elas gostam de ir à escola e são assíduas justamente pela possibilidade de que, por meio da atenção 
que os professores potencialmente podem dispensar a elas, seja possível obterem aquilo que julgam necessitar ao reestabelecimento de seu desenvolvimento emocional.

Os professores apontaram que, embora essas crianças se relacionem bem com eles, é difícil lidar com a teimosia, mau humor, reações agressivas diante de contrariedade e conflitos outros com as crianças. Afirmam que suas estratégias não têm efeito e que gostariam de ajuda. Nestas condições, o trabalho do professor está ligado à imposição de limites, com respeito pela criança, se colocando na posição de orientador, mediador de conflitos, utilizando o acolhimento ou até mesmo a contenção, se for o caso.

Grande parte das crianças tiveram marcos de vida importantes que contribuíram para o surgimento das manifestações excessivas de agressividade. Tais marcos, muitas vezes, podem ser considerados acontecimentos naturais da vida cotidiana, caracterizados como difíceis de serem vivenciados, tanto pelas famílias quanto pelas crianças. Diante disso, o os professores precisam estar atentos às comunicações das crianças, de forma a refletirem acerca de suas necessidades afetivas e educacionais.

\section{CONCLUSÃO}

Essa pesquisa está possibilitando conhecer um pouco as singularidades das crianças que manifestam agressividade no contexto escolar. A partir deste estudo, até o momento, pudemos desconstruir algumas considerações correntes entre os educadores sobre as crianças e suas famílias.

Compreende-se que grande parte das crianças que manifestam agressividade, pelo menos no grupo estudado, possui características semelhantes no que diz respeito à sexo, frequência à escola e período matriculado. Com relação aos comportamentos, sobressaem as categorias "nervosa", "agitação", "falta de concentração", "dificuldades em cumprir regras", "não tem limites", além da diversidade de formas que as crianças utilizam para manifestarem a agressividade.

Ainda, foi notório que algumas situações do entorno podem estar relacionadas às manifestações agressivas, sendo estas uma forma das crianças expressarem os conflitos pelos quais estavam passando no momento, visando obter ajuda do ambiente escolar, local em que se sentem seguras.

Concluímos que, a partir do conhecimento acerca do perfil das crianças que manifestam agressividade, os professores terão elementos para refletir sobre essas manifestações e intervir de modo a propiciar o auxílio que as crianças buscam no controle de suas emoções e, também, a desenvolverem formas alternativas de se relacionarem com elas, acolhendo-as.

\section{REFERÊNCIAS}

LÜDKE, M.; ANDRÉ, M. E. D. A. Pesquisa em Educação: abordagens qualitativas. São Paulo: EPU, 1986.

WINNICOTT, D. W. A criança e o seu mundo. 6 ed. Rio de Janeiro: LTC

- Livros Técnicos e Científicos Editora S.A., 1982.

WINNICOTT, D. W. Privação e delinqüência. 4 ed. São Paulo: Martins Fontes,2005. 